\title{
A Practical Synthesis of a $\gamma$-Secretase Inhibitor
}

Jeremy P. Scott, ${ }^{* \dagger}$ David R. Lieberman, ${ }^{* \dagger}$ Olivier M. Beureux, ${ }^{\dagger}$ Karel M. J. Brands, ${ }^{\dagger}$ Antony J. Davies, ${ }^{\dagger}$ Andrew W. Gibson, ${ }^{\dagger}$ Deborah C. Hammond ${ }^{\dagger}$ Chris J. McWilliams, ${ }^{*}$ Gavin W. Stewart, ${ }^{\dagger}$ Robert D. Wilson ${ }^{\dagger}$ and Ulf-H. Dolling ${ }^{\dagger}$

${ }^{\dagger}$ Department of Process Research, Merck Sharp \& Dohme Research Laboratories, Hertford Road, Hoddesdon, Hertfordshire, EN11 9BU and

${ }^{*}$ Department of Process Research, Merck Research Laboratories, P. O. BOX 2000, Rahway, New Jersey 07065.

jeremy_scott@merck.com; dave_lieberman@merck.com

\section{Supporting Information}

Table of Contents

Page

1. General experimental

$S-1$

2. Experimental for preparation of $\mathbf{2 , 8 , 1 0}$ and $\mathbf{1 2}$

S-1 to $S-3$

3. Crystal data and structure refinement for vinyl sulfone 6 (CCDC 236716) S-3

4. Crystal data and structure refinement for cyclohexanone 5 (CCDC 236717) S-4

5. ${ }^{1} \mathrm{H}$ and ${ }^{13} \mathrm{C}$ NMR spectra

$S-5$ to $S-27$

\section{General experimental}

All reactions were carried out under a nitrogen atmosphere. All solvents and reagents were purchased from commercial sources and were used without further purification. ${ }^{1} \mathrm{H}$ and ${ }^{13} \mathrm{C}$ NMR were recorded on at $400 \mathrm{MHz}$ with chemical shifts reported relative to residual proton solvent peaks. Melting points (open capillary) are uncorrected. All yields and w/t\% were determined by reverse phase HPLC assay using purified standards.

2-[[(4-Chlorophenyl)thio]methyl]-1,4-difluorobenzene (8). 4-Chlorothiophenol (253 g, $1.75 \mathrm{~mol})$ was dissolved in $\mathrm{EtOH}(1265 \mathrm{~mL})$ and $2 \mathrm{M}$ sodium hydroxide solution $(901$ $\mathrm{mL}$ ) was added, maintaining the temperature below $20{ }^{\circ} \mathrm{C}$. A solution of 2,5difluorobenzyl bromide $(355 \mathrm{~g}, 1.72 \mathrm{~mol})$ in $\mathrm{EtOH}(250 \mathrm{~mL})$ was added dropwise to the thiolate solution, maintaining the temperature below $15{ }^{\circ} \mathrm{C}$. Upon completion of the reaction, water $(1000 \mathrm{~mL})$ was added. The resulting slurry was aged at $5{ }^{\circ} \mathrm{C}$ and then filtered. The cake was washed sequentially with a cold mixture of $\mathrm{EtOH}$ and water (40:60, respectively; $500 \mathrm{~mL}$ ) and then water $(500 \mathrm{~mL})$. Drying in vacuo at ambient 
temperature furnished the title compound $(462 \mathrm{~g}, 100 \%) .{ }^{1} \mathrm{H} \mathrm{NMR}\left(400 \mathrm{MHz}, \mathrm{CD}_{2} \mathrm{Cl}_{2}\right) \delta$ 7.20-7.13 (m, 4H), 6.93-6.79 (m, 3H), $3.99(\mathrm{~s}, 2 \mathrm{H}) ;{ }^{13} \mathrm{C}$ NMR $\left(100 \mathrm{MHz}, \mathrm{CD}_{2} \mathrm{Cl}_{2}\right) \delta$ $158.5(\mathrm{~d}, J=241 \mathrm{~Hz}), 156.8(\mathrm{~d}, J=241 \mathrm{~Hz}), 133.6,133.0,132.2,129.0,126.5(\mathrm{dd}, J=7$, $17 \mathrm{~Hz}), 116.9$ (dd, $J=4,25 \mathrm{~Hz}), 116.4(\mathrm{dd}, J=8,24 \mathrm{~Hz}), 115.4$ (dd, $J=9,24 \mathrm{~Hz}), 32.2$; IR $v\left(\mathrm{~cm}^{-1}\right) 1493,1474,1203,1192,1090 ; \mathrm{mp} \mathrm{38-39}{ }^{\circ} \mathrm{C}$; Anal. Calcd. For $\mathrm{C}_{13} \mathrm{H}_{9} \mathrm{ClF}_{2} \mathrm{~S}$; C, 57.67; H, 3.35; F, 14.04. Found: C, 57.52; H, 3.25; F, 13.98.

4-[(4-Chlorophenyl)sulfonyl]-4-(2,5-difluorophenyl)cyclohex-1-en-1-yl

trifluoromethanesulfonate (10). To a stirred solution of diisopropylamine $(8.1 \mathrm{~g}, 80$ mmol $)$ in THF $(50 \mathrm{~mL})$ at $-75^{\circ} \mathrm{C}$ was added BuLi over 20 min maintaining the internal temp. below $-60{ }^{\circ} \mathrm{C}$. The resultant solution was allowed to warm to ambient temperature and then added dropwise over $30 \mathrm{~min}$ to a solution of cyclohexanone 5 (26.7 g, $70 \mathrm{mmol})$ in THF $(270 \mathrm{~mL})$ at $-75{ }^{\circ} \mathrm{C}$. After a $30 \mathrm{~min}$ age, a solution of $2-[\mathrm{N}, \mathrm{N}-$ bis(trifluoromethylsulfonyl)amino]-5-chloropyridine (30.0 g, $76 \mathrm{mmol})$ in THF (100 mL) was added dropwise over $30 \mathrm{~min}$. The mixture was allowed to warm to ambient temperature, aged $1 \mathrm{~h}$ and then quenched with water $(800 \mathrm{~mL})$. Extraction with isopropyl acetate $(500 \mathrm{~mL})$ afforded an organic layer which was washed with citric acid $(5 \mathrm{w} / \mathrm{t} \%$, $400 \mathrm{~mL})$ and water $(400 \mathrm{~mL})$. Drying $\left(\mathrm{Na}_{2} \mathrm{SO}_{4}\right)$, evaporation in vacuo and silica gel chromatography afforded the title compound $(24.0 \mathrm{~g}, 67 \%) .{ }^{1} \mathrm{H} \mathrm{NMR}\left(400 \mathrm{MHz}, \mathrm{CDCl}_{3}\right)$ $\delta$ 7.45-7.38 (m, 4H), 7.14-7.04 (m, 2H), 6.92-6.85 (m, 1H), 5.82-5.76 (m, 1H), 3.16-3.11 $(\mathrm{m}, 2 \mathrm{H}), 3.05-2.95(\mathrm{~m}, 1 \mathrm{H}), 2.58-2.45(\mathrm{~m}, 2 \mathrm{H}), 2.25-2.15(\mathrm{~m}, 1 \mathrm{H}) ;{ }^{13} \mathrm{C}$ NMR $(100 \mathrm{MHz}$, $\left.\mathrm{CDCl}_{3}\right) \delta 159.9-159.7 \&$ 157.4-157.3 (2C, overlapping resonances), 147.9, 141.4, 133.3, 131.5, 129.1, 121.0-119.8 (broad), 118.6-118.1 (3C, overlapping resonances), 116.7, 114.7, 67.4, $28.8(\mathrm{~d}, J=7.1 \mathrm{~Hz}), 27.0(\mathrm{~d}, J=7.1 \mathrm{~Hz}), 25.6$; IR $v\left(\mathrm{~cm}^{-1}\right) 1579,1506,1473$, 1418, 1314, 1203, 1143, 1039; mp 88-90 ${ }^{\circ} \mathrm{C}$; Anal. Calcd for $\mathrm{C}_{19} \mathrm{H}_{14} \mathrm{ClF}_{5} \mathrm{O}_{5} \mathrm{~S}_{2}$ : C, 44.15; H 2.73. Found: C 44.17; H 2.70.

\section{3-[4-[(4-Chlorophenyl)sulfonyl]-4-(2,5-difluorophenyl)cyclohex-1-en-yl]propanoic}

acid (2). To a stirred solution of enol triflate $\mathbf{1 0}(2.58 \mathrm{~g}, 5.0 \mathrm{mmol})$ in THF $(12.5 \mathrm{~mL})$ was added dichlorobis(triphenylphosphine) palladium $(0.35 \mathrm{~g}, 0.5 \mathrm{mmol})$. The resultant solution was heated to $50{ }^{\circ} \mathrm{C}$ and 3-ethoxy-3-oxopropylzinc bromide $(15.0 \mathrm{~mL}$ of a $0.5 \mathrm{M}$ in THF solution) was added over $15 \mathrm{~min}$. After aging for a further $1.5 \mathrm{~h}$, the mixture was cooled and then partitioned between aqueous ammonium chloride $(10 \mathrm{w} / \mathrm{t} \%, 50 \mathrm{~mL})$ and isopropyl acetate $(100 \mathrm{~mL})$. The organic layer was washed with brine $(10 \mathrm{w} / \mathrm{t} \%, 50 \mathrm{~mL})$, evaporated in vacuo and purified by silica gel chromatography (15\% ethyl acetate in hexane) to afford $1.9 \mathrm{~g}$ of the coupled product. This residue was taken up in a mixture of THF $(40 \mathrm{~mL})$ and water $(15 \mathrm{~mL})$ and $\mathrm{LiOH} \cdot \mathrm{H}_{2} \mathrm{O}(6.6 \mathrm{~g}, 157 \mathrm{mmol})$ was added. Following heating at $65^{\circ} \mathrm{C}$ for $5 \mathrm{~h}$, the solution was acidified with $2 \mathrm{M} \mathrm{HCl}(50 \mathrm{~mL})$ and extracted with isopropyl acetate $(2 \times 50 \mathrm{~mL})$. The combined organic layers were washed with water $(50 \mathrm{~mL})$ and evaporated to dryness in vacuo. The crude product was purified by flash chromatography to afford the title compound ( $1.3 \mathrm{~g}, 59 \%$ over 2 steps). ${ }^{1} \mathrm{H}$ NMR (400 MHz, DMSO) $\delta 11.88$ (br s, $1 \mathrm{H}), 7.60$ (d, $J=8.6 \mathrm{~Hz}, 1 \mathrm{H}), 7.40(\mathrm{~d}, J=8.6 \mathrm{~Hz}, 1 \mathrm{H})$, 7.22-7.26 (m, 1H), 7.05-7.17 (m, 2H), $5.33(\mathrm{~d}, J=5.0 \mathrm{~Hz}, 1 \mathrm{H}), 2.91-3.03(\mathrm{~m}, 1 \mathrm{H}), 2.78-$ $2.83(\mathrm{~m}, 1 \mathrm{H}), 2.58-2.68(\mathrm{~m}, 1 \mathrm{H}), 2.46(\mathrm{t}, J=1.7 \mathrm{~Hz}, 2 \mathrm{H}), 1.90-2.17(\mathrm{~m}, 6 \mathrm{H}), 1.61-1.74$ $(\mathrm{m}, 1 \mathrm{H}) ;{ }^{13} \mathrm{C}$ NMR $(100 \mathrm{MHz}, \mathrm{DMSO}) \delta 174.2,159.9(\mathrm{~d}, J=82 \mathrm{~Hz}), 157.5(\mathrm{~d}, J=73$ Hz), 140.1, 137.2, 134.1, 132.2, 129.6, 121.44 (dd, $J=7.7,12 \mathrm{~Hz}), 119.3$ (dd, $J=4.0,30$ 
$\mathrm{Hz}), 118.8(\mathrm{dd}, J=8.8,22 \mathrm{~Hz}), 118.5(\mathrm{dd}, J=6.0,24 \mathrm{~Hz}), 117.0,69.0(\mathrm{~d}, J=3.6 \mathrm{~Hz})$, 32.6, 31.4, 29.7 (d, $J=5.1 \mathrm{~Hz}), 26.9$ (d, $J=7.4 \mathrm{~Hz}), 26.4$; IR $\vee\left(\mathrm{cm}^{-1}\right)$ 1710, 1580, 1494, 1411, 1303, 1256, 1148, 1136, 1087; mp 185-189 ${ }^{\circ} \mathrm{C}$; Anal. Calcd. For $\mathrm{C}_{21} \mathrm{H}_{19} \mathrm{ClF}_{2} \mathrm{O}_{4} \mathrm{~S}$ C, 57.21; H, 4.34; Found. C, 57.22; H, 4.09.

\section{Trans-3-[4-[(4-chlorophenyl)sulfonyl]-4-(2,5-difluorophenyl)cyclohexyl]propanoic} acid (12). A mixture of 2 (100 mg, $0.23 \mathrm{mmol})$ and $5 \% \mathrm{Rh} / \mathrm{C}(50 \mathrm{mg})$ in EtOAc $(1.5 \mathrm{~mL})$ was stirred under an atmosphere of $90 \mathrm{psig}_{2}$ and aged for $18 \mathrm{~h}$ at $22{ }^{\circ} \mathrm{C}$. HPLC analysis of the reaction mixture indicated 98 area\% conversion to a 93:7 mixture of $\mathbf{1 2}$ and $\mathbf{1}$, respectively. The mixture was filtered through Celite ${ }^{\circledR}$, and washed with EtOAc. Concentration of the combined filtrates yielded a light yellow oil (98 mg). Data for 12: ${ }^{1} \mathrm{H}$ NMR $\left(400 \mathrm{MHz}, \mathrm{CDCl}_{3}\right)$ $\delta$ 7.33-7.39 (m, $\left.4 \mathrm{H}\right)$, 7.02-7.08 (m, 1H), 6.83-6.86 (m, 1H), 3.0-2.5 (br m, 2H), 2.28 (t, $J=7.5 \mathrm{~Hz}, 2 \mathrm{H}), 2.02-2.20$ (br m, 2H), 1.79-1.80 (m, 2H), $1.38-1.54(\mathrm{~m}, 3 \mathrm{H}), 0.77-0.98(\mathrm{~m}, 2 \mathrm{H}) ;{ }^{13} \mathrm{C} \mathrm{NMR}\left(100 \mathrm{MHz}, \mathrm{CDCl}_{3}\right) \delta 179.6,159.9(\mathrm{dd}, J$ $=2.3,43 \mathrm{~Hz}), 157.4(\mathrm{dd}, J=2.3,38 \mathrm{~Hz}), 140.6,133.4,131.4,128.6,121.3(\mathrm{dd}, J=7.2$, $11 \mathrm{~Hz}), .118 .9(\mathrm{dd}, J=4.4,25 \mathrm{~Hz}), 118.1(\mathrm{dd}, J=8.4,29 \mathrm{~Hz}), 117.8(\mathrm{dd}, J=10,24 \mathrm{~Hz})$, 70.9 (d, $J=4.0 \mathrm{~Hz}$ ), 36.1, 31.4, 31.3, 29.7, 29.6, 28.3 (v. br), 27.9 (v. br); HRMS (+ESI) calcd for $\mathrm{C}_{21} \mathrm{H}_{25} \mathrm{NClF}_{2} \mathrm{O}_{4}\left(\mathrm{M}+\mathrm{NH}_{4}\right)$ requires 460.1161; found 460.1160.

\section{Crystal data and structure refinement for vinyl sulfone 6 (CCDC 236716)}

A single crystal was selected for single crystal x-ray data collection on a Bruker Smart Apex system. The crystal was colorless rod with dimensions of $0.798 \mathrm{~m}$ x $0.49 \mathrm{~m} \times 0.30$ $\mathrm{m}$. The unit cell was collected on 1 second scan rate and auto-indexing gave the cell setting to be triclinic with the space group of P-1. The structure was solved after data collection of 1 second scan rate for a full quadrant. See Table 1. 


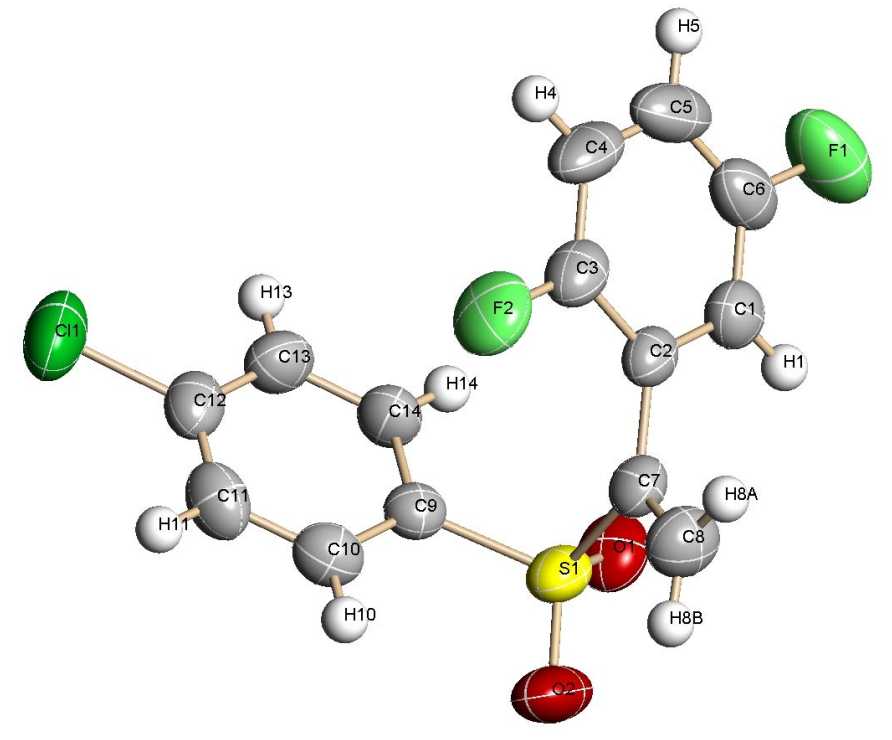

Table 1.

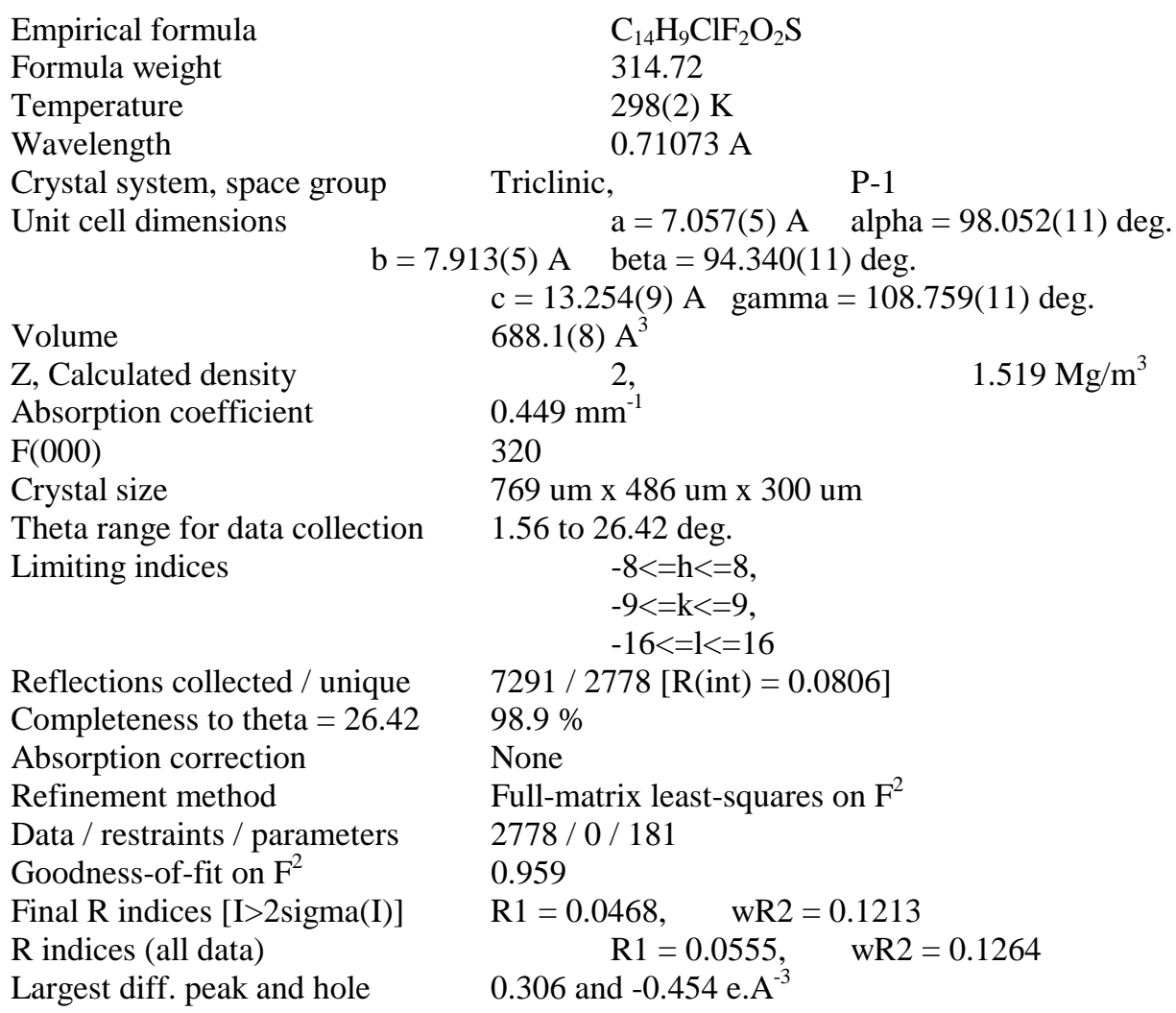




\section{Crystal data and structure refinement for cyclohexanone 5 (CCDC 236717)}

A single crystal was selected for single crystal x-ray data collection on a Bruker Smart Apex system. The crystals were colorless polyhedron with dimensions of $0.44 \mathrm{~mm} \mathrm{x}$ $0.30 \mathrm{~mm} \times 0.05 \mathrm{~mm}$. The unit cell was collected on 10 second scan rate and manual indexing gave the cell setting to be orthorhombic. The structure was solved in the orthorhombic Pca2(1) space group after a quadrant of data collection using 10 second scan rate. Although the molecule is achiral, it has crystallized as a single atropisomer due to hindered rotation about the sp3 -sp3 bonds at the sulfur atom. See Table 2.

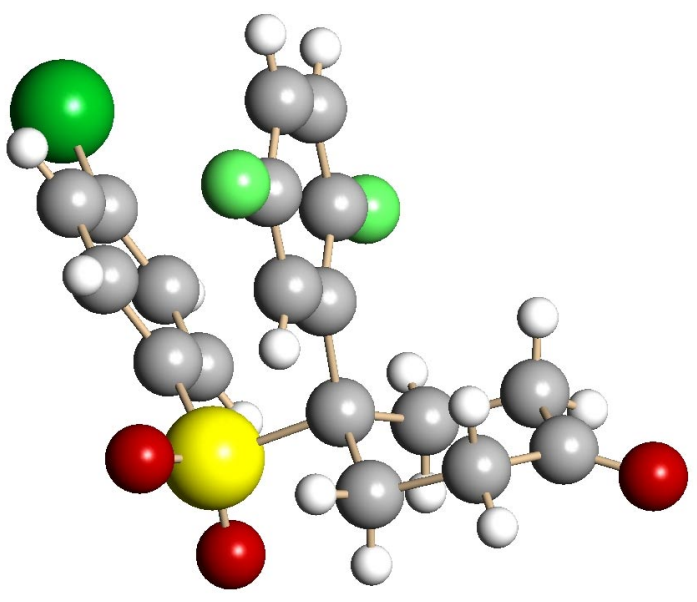

Table 2.

Empirical formula

Formula weight

Temperature

Wavelength

Crystal system, space group

Unit cell dimensions

Volume

$\mathrm{Z}$, Calculated density

Absorption coefficient

$\mathrm{F}(000)$

Crystal size

Theta range for data collection

Limiting indices

Reflections collected / unique

Completeness to theta $=26.47$

Absorption correction

Refinement method

Data / restraints / parameters

Goodness-of-fit on $\mathrm{F}^{2}$
$\mathrm{C}_{18} \mathrm{H}_{15} \mathrm{Cl} \mathrm{F}_{2} \mathrm{O}_{3} \mathrm{~S}$

384.81

298(2) K

$0.71073 \mathrm{~A}$

Orthorhombic, Pca2(1)

$$
\mathrm{a}=15.450(10) \mathrm{A} \quad \text { alpha }=90 \mathrm{deg} .
$$

$\mathrm{b}=10.490(7) \mathrm{A}$

beta $=90 \mathrm{deg}$.

$\mathrm{c}=10.828(7) \mathrm{A}$ gamma $=90 \mathrm{deg}$.

$1755(2) \mathrm{A}^{3}$

$0.371 \mathrm{~mm}^{-1}$

$1.456 \mathrm{Mg} / \mathrm{m}^{3}$

792

$0.44 \times 0.30 \times 0.05 \mathrm{~mm}$

1.94 to $26.47 \mathrm{deg}$.

$-19<=\mathrm{h}<=19$,

$-12<=\mathrm{k}<=13$,

$-12<=1<=13$

$13312 / 3373$ [R(int $)=0.1182]$

$99.6 \%$

None

Full-matrix least-squares on $\mathrm{F}^{2}$

3373 / 1 / 226

0.957 
Final R indices [I>2sigma(I)]

$\mathrm{R}$ indices (all data)

Absolute structure parameter

Largest diff. peak and hole
$\mathrm{R} 1=0.0515$,

$\mathrm{R} 1=0.0622$,

$-0.01(9)$

0.303 and -0.172 e. $\mathrm{A}^{-3}$
$\mathrm{wR} 2=0.1173$

$\mathrm{wR} 2=0.1225$ 

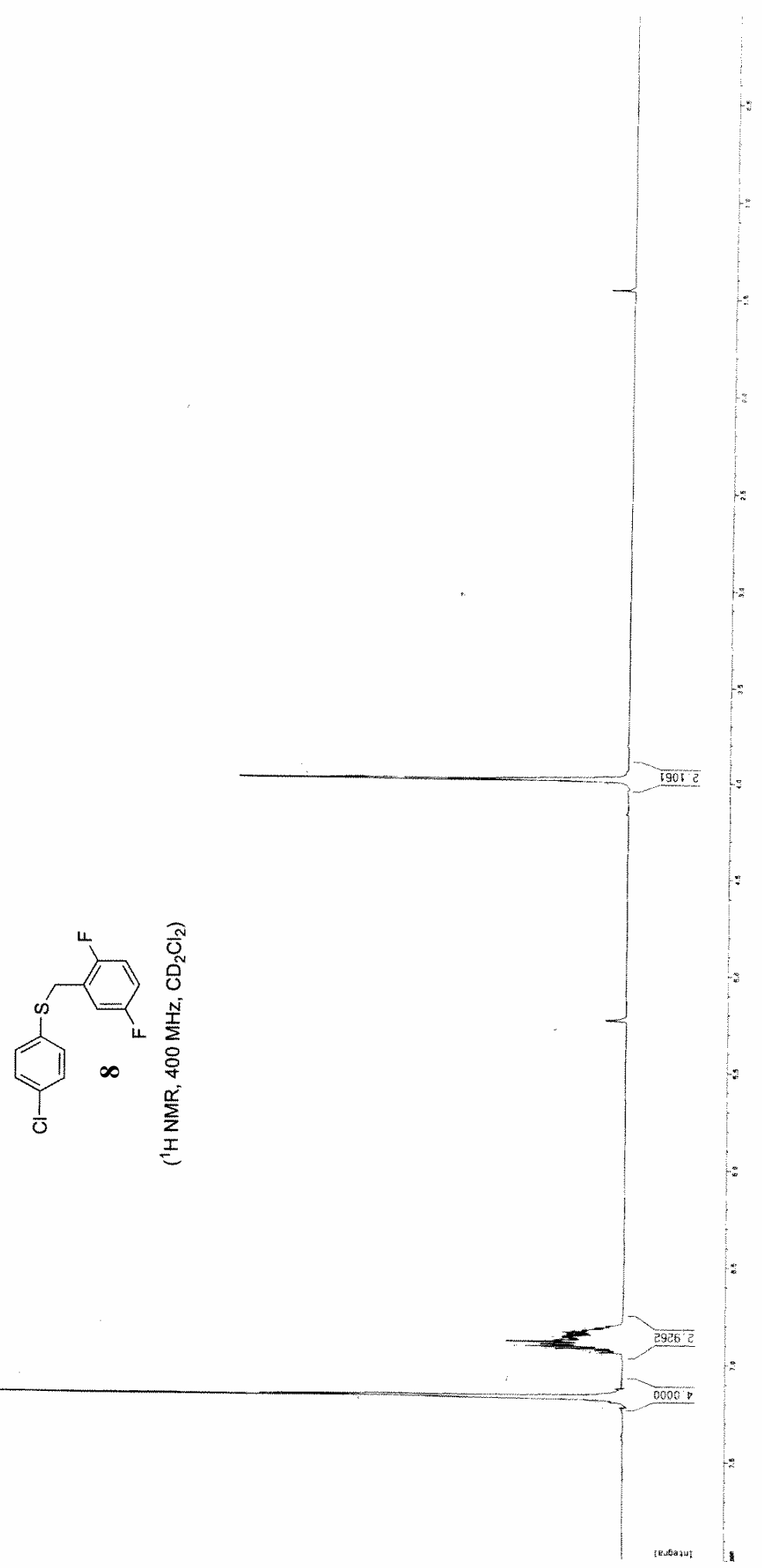


$$
4
$$




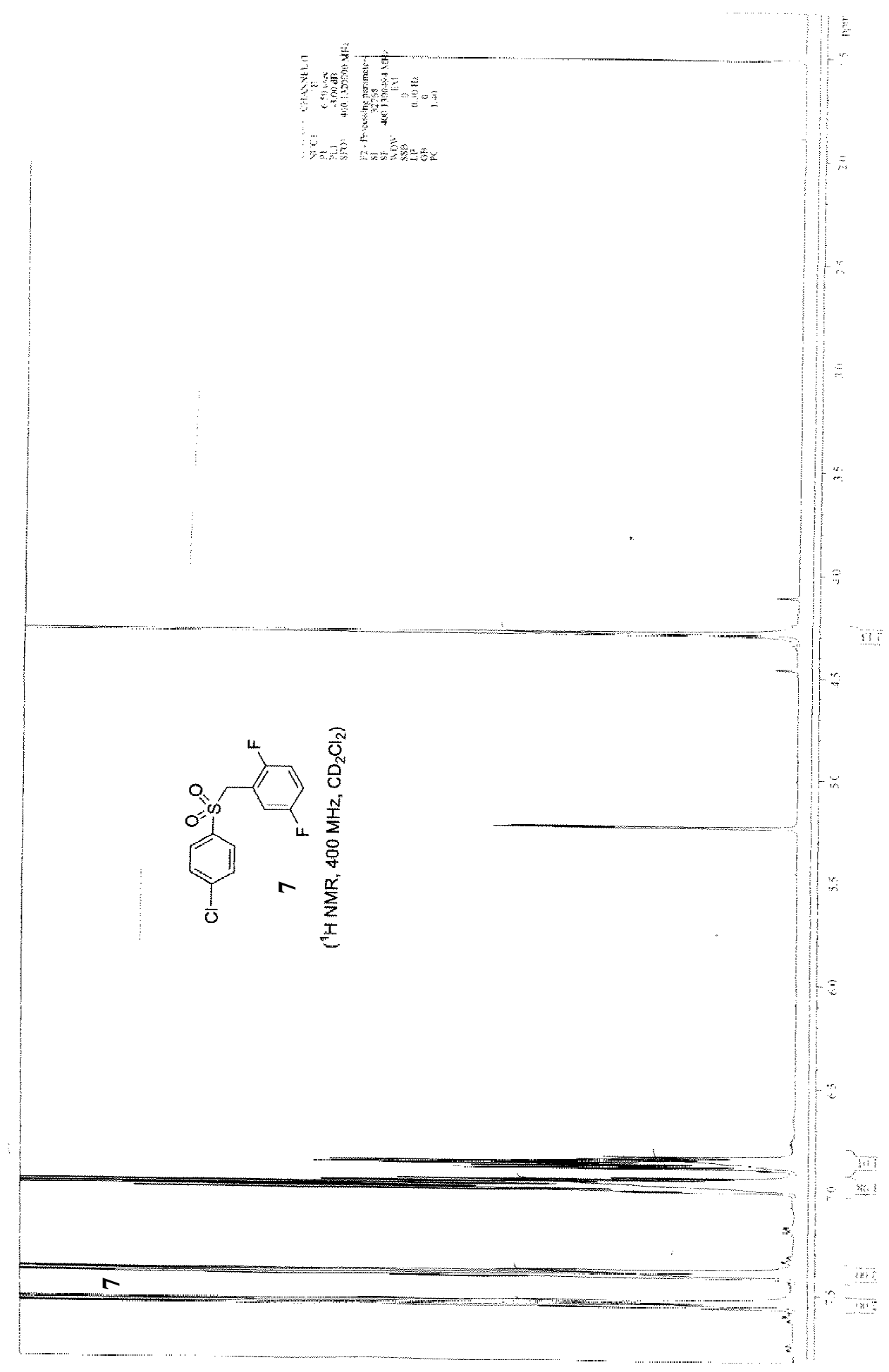




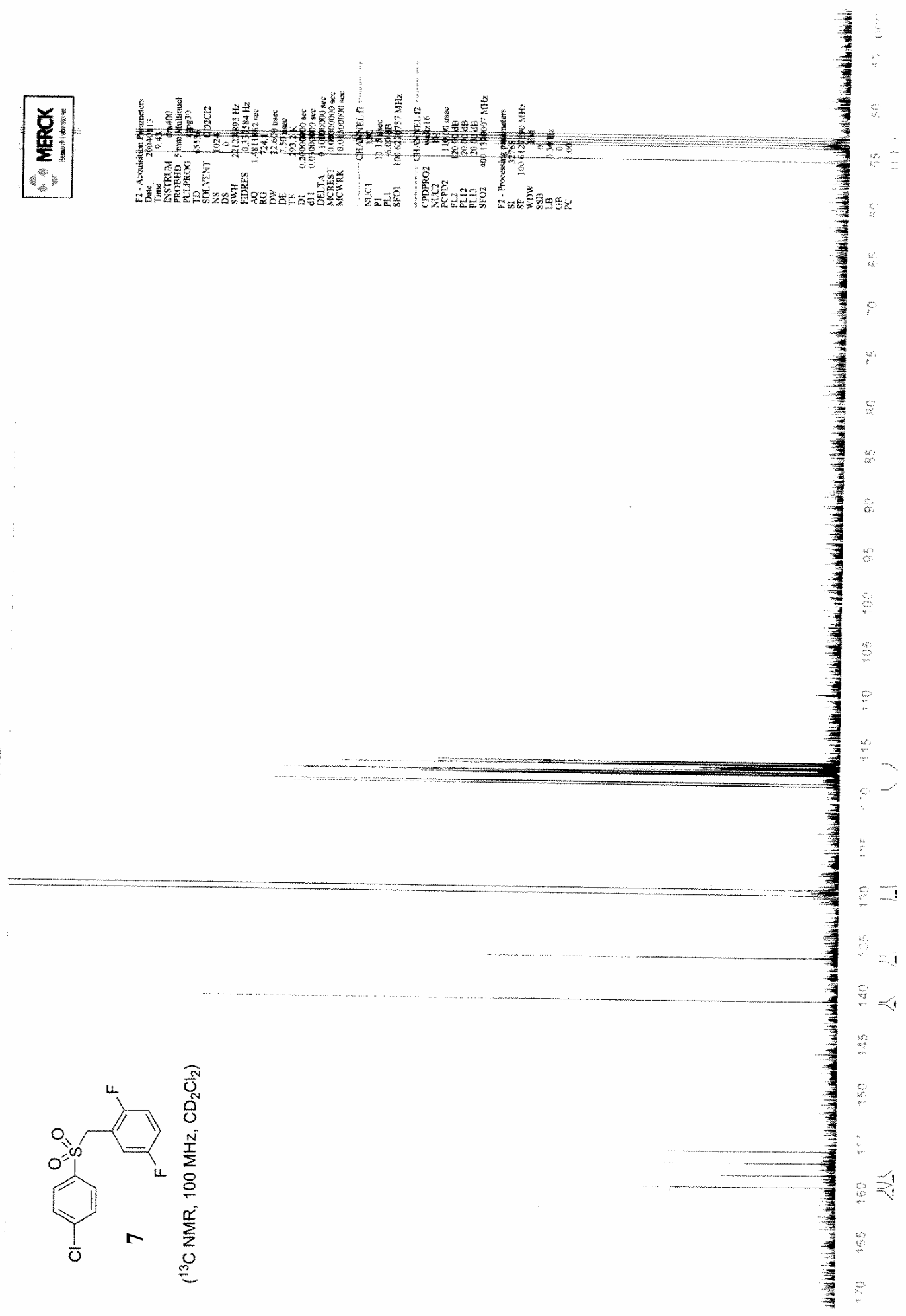




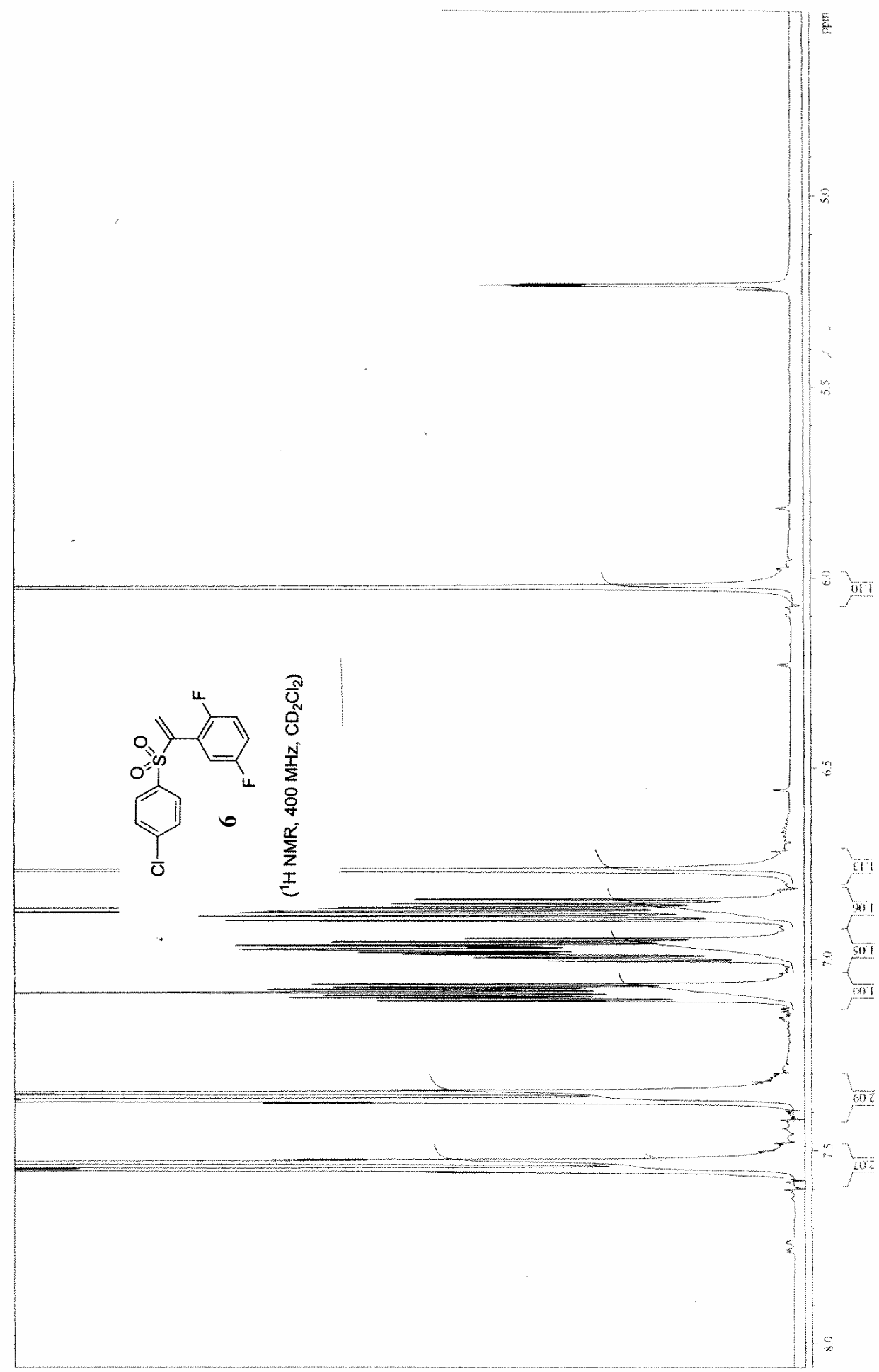




$$
7
$$




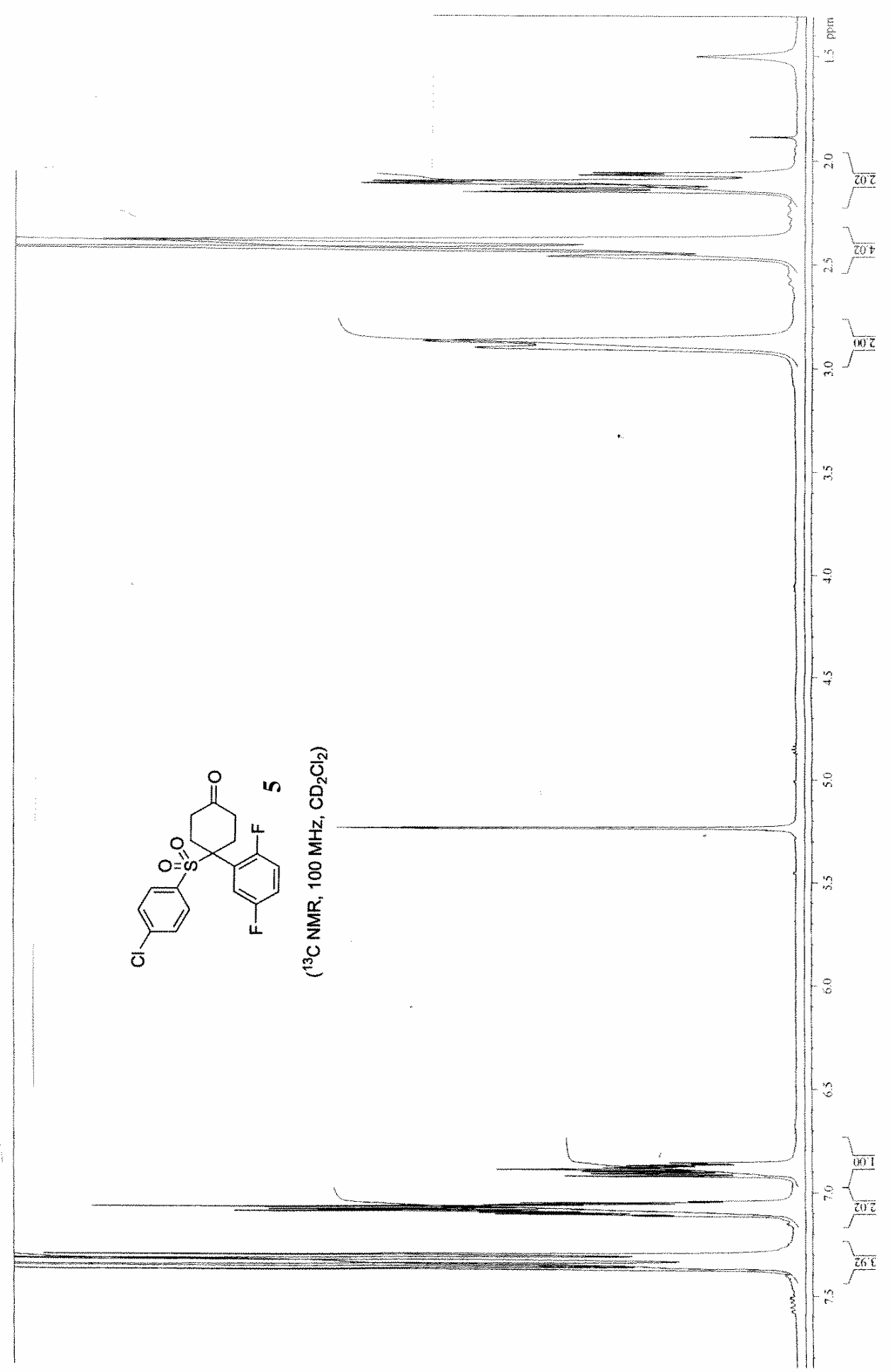




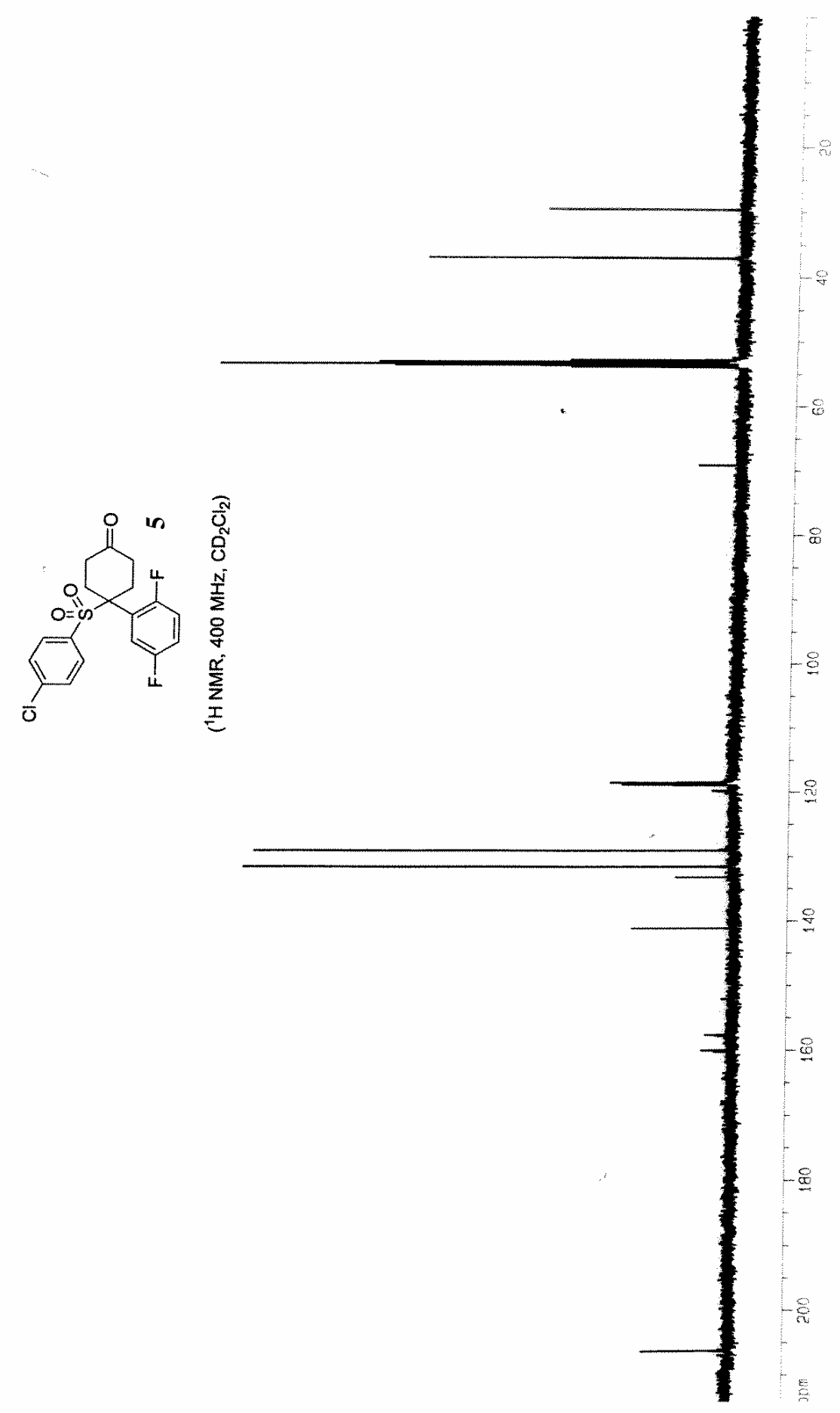




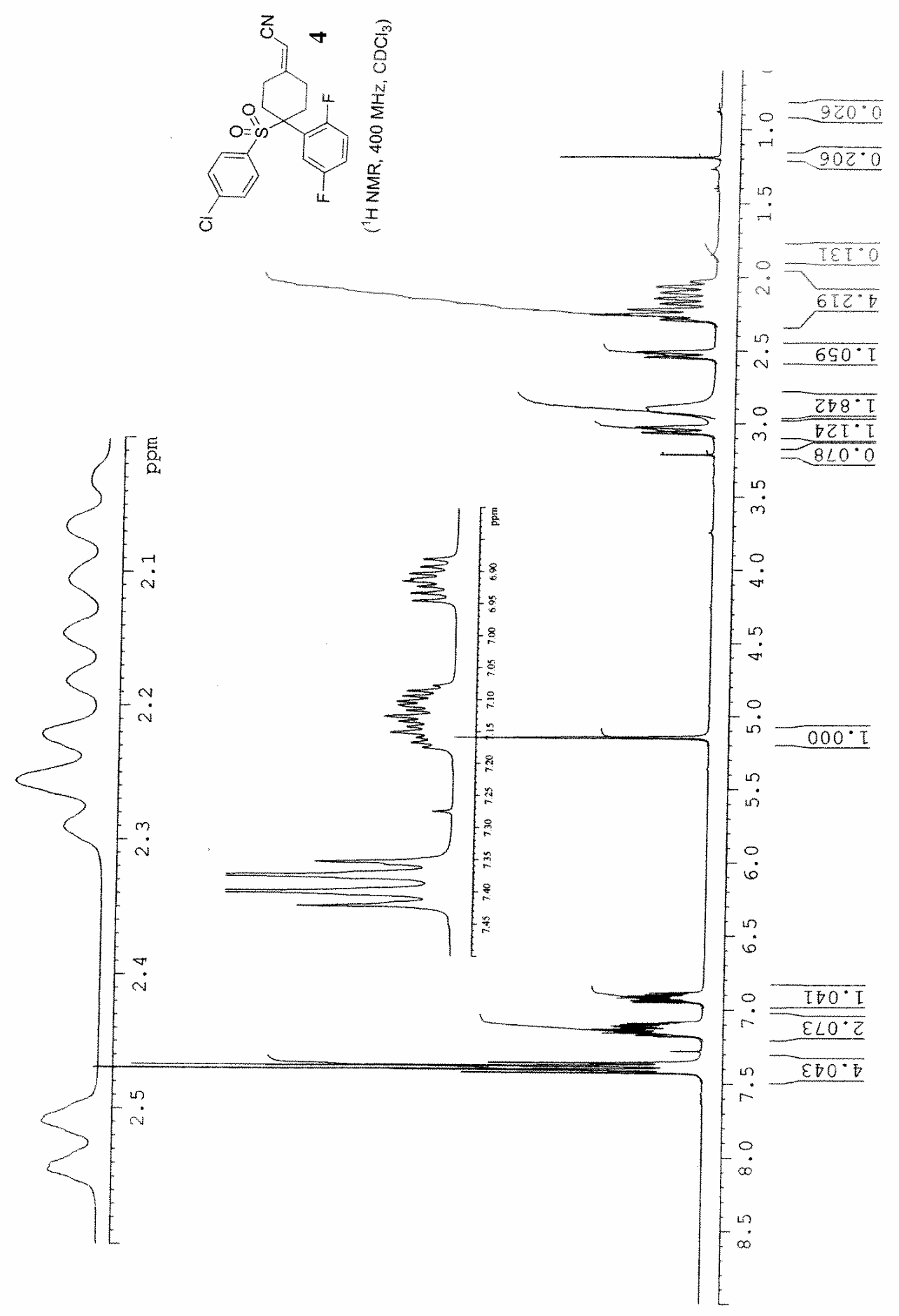



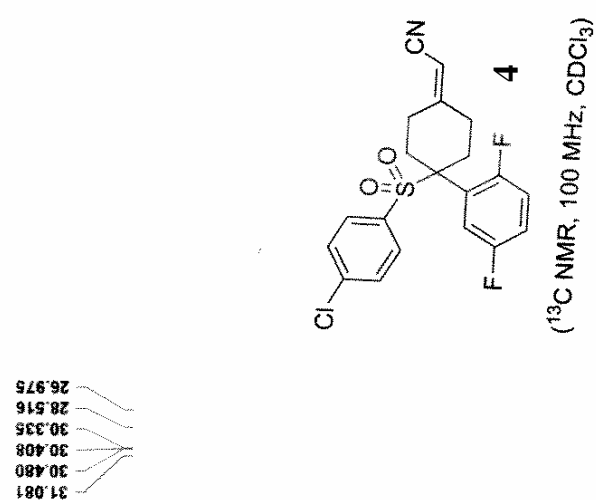

$91+6 v-\ldots$
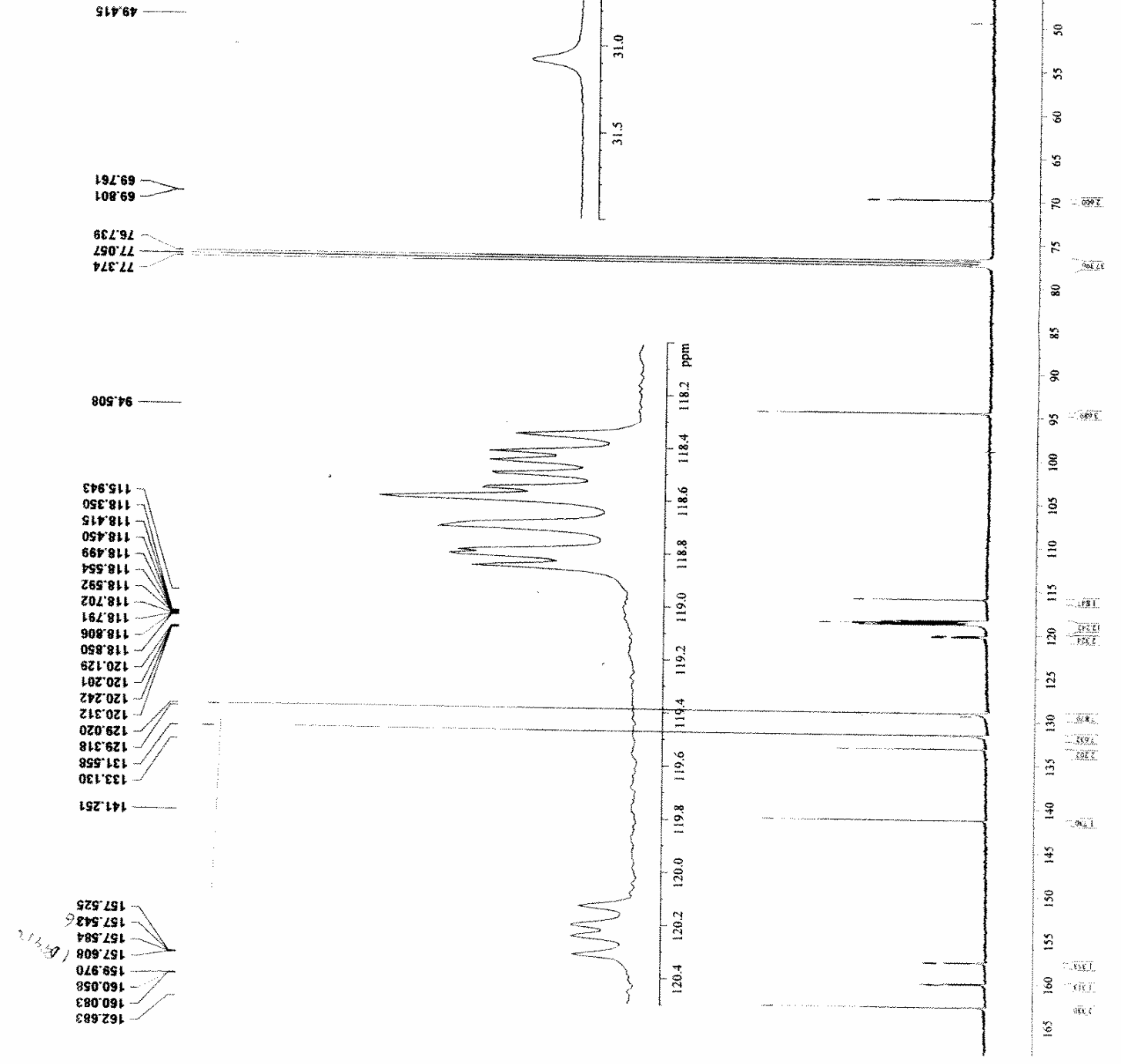


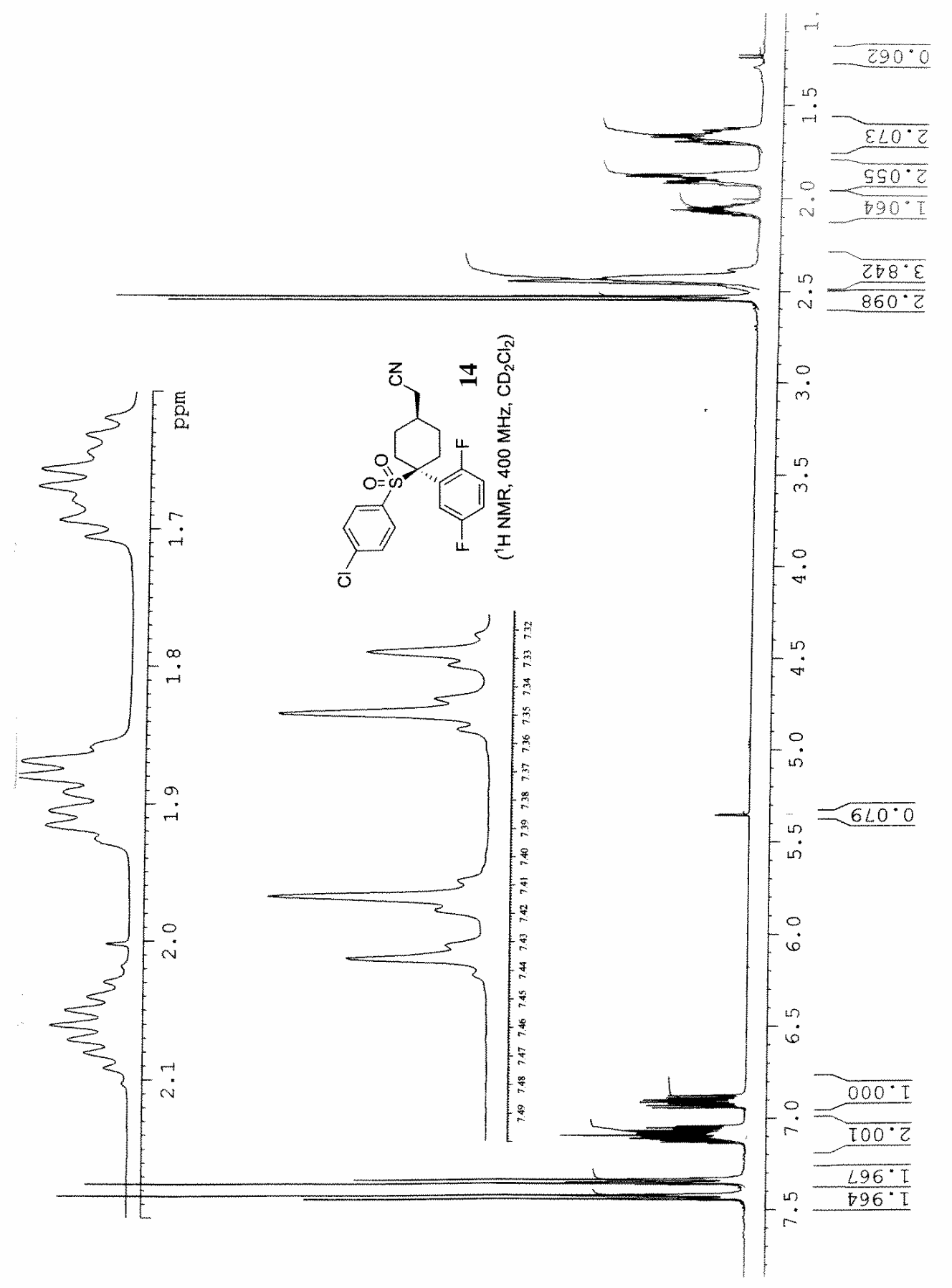




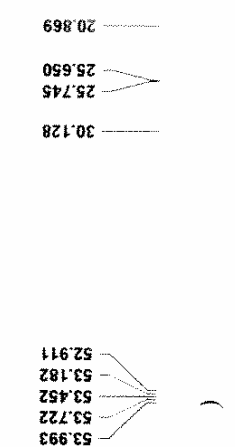

22LEs

$95869->$
$280^{\circ} 69->$
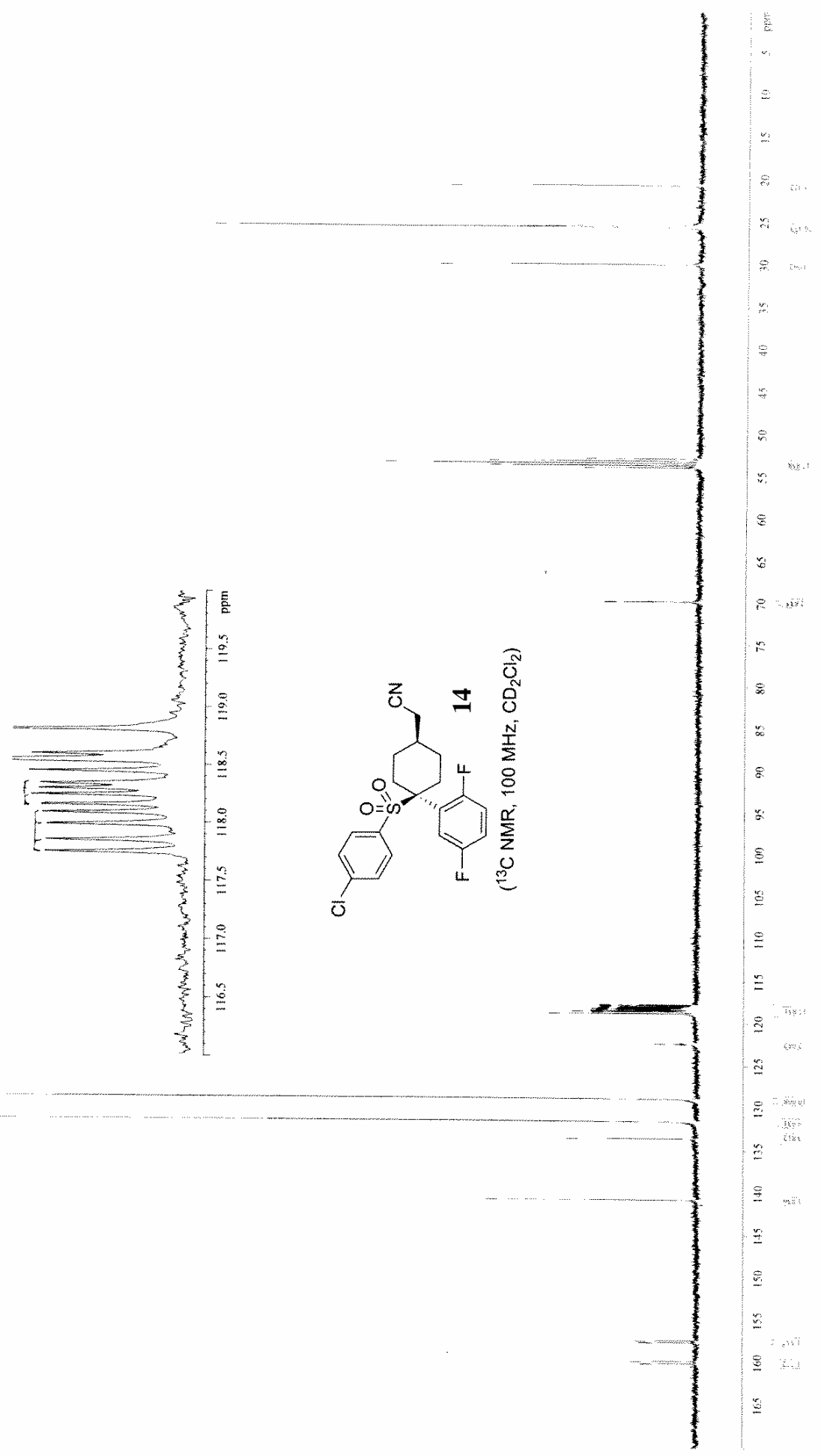

90241-

$208211-$

c80811 -

เsibti

LEC 811 -

LEC 81L
HEE $84 L$

DEE 81.

ctse11-

169811

zos 811

6LEZZ1 -

9ts'te

LESEEI

$0 L L 0+1$

6Eع ISI

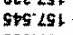

8952151

$6+2.651$

40091.
270091 

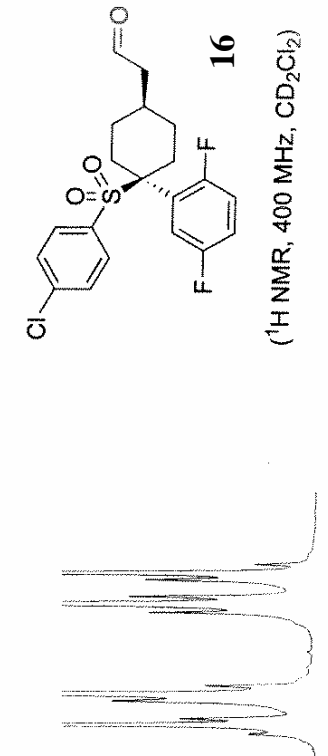

暿

8

i.

8

$5 \overline{8061}$

i

8

r

8

0

8

r

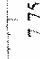

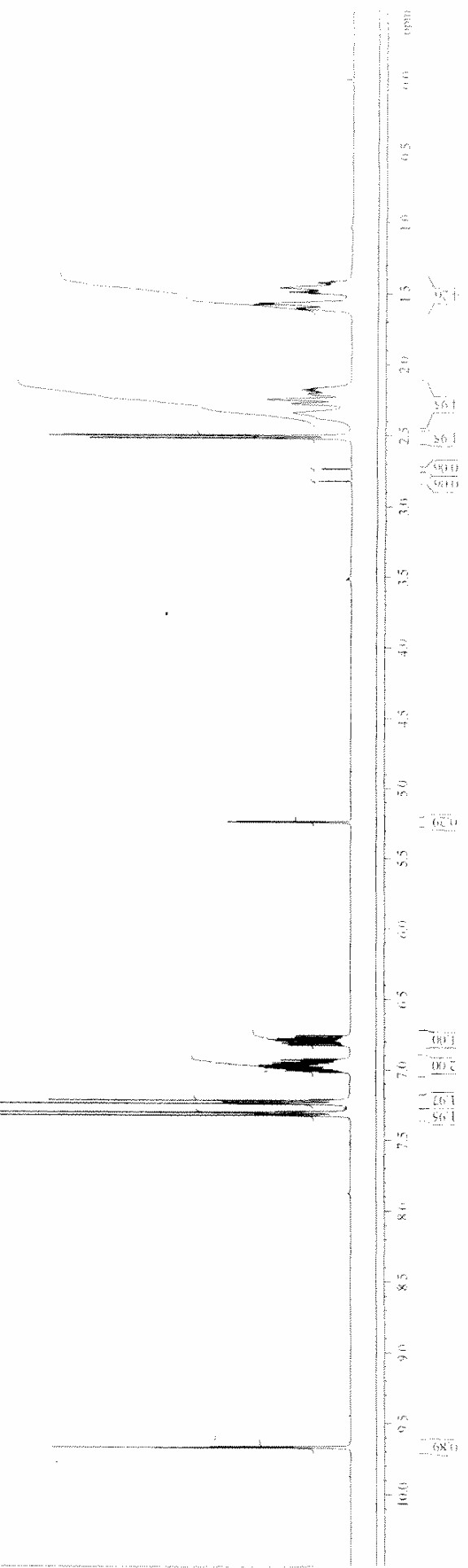




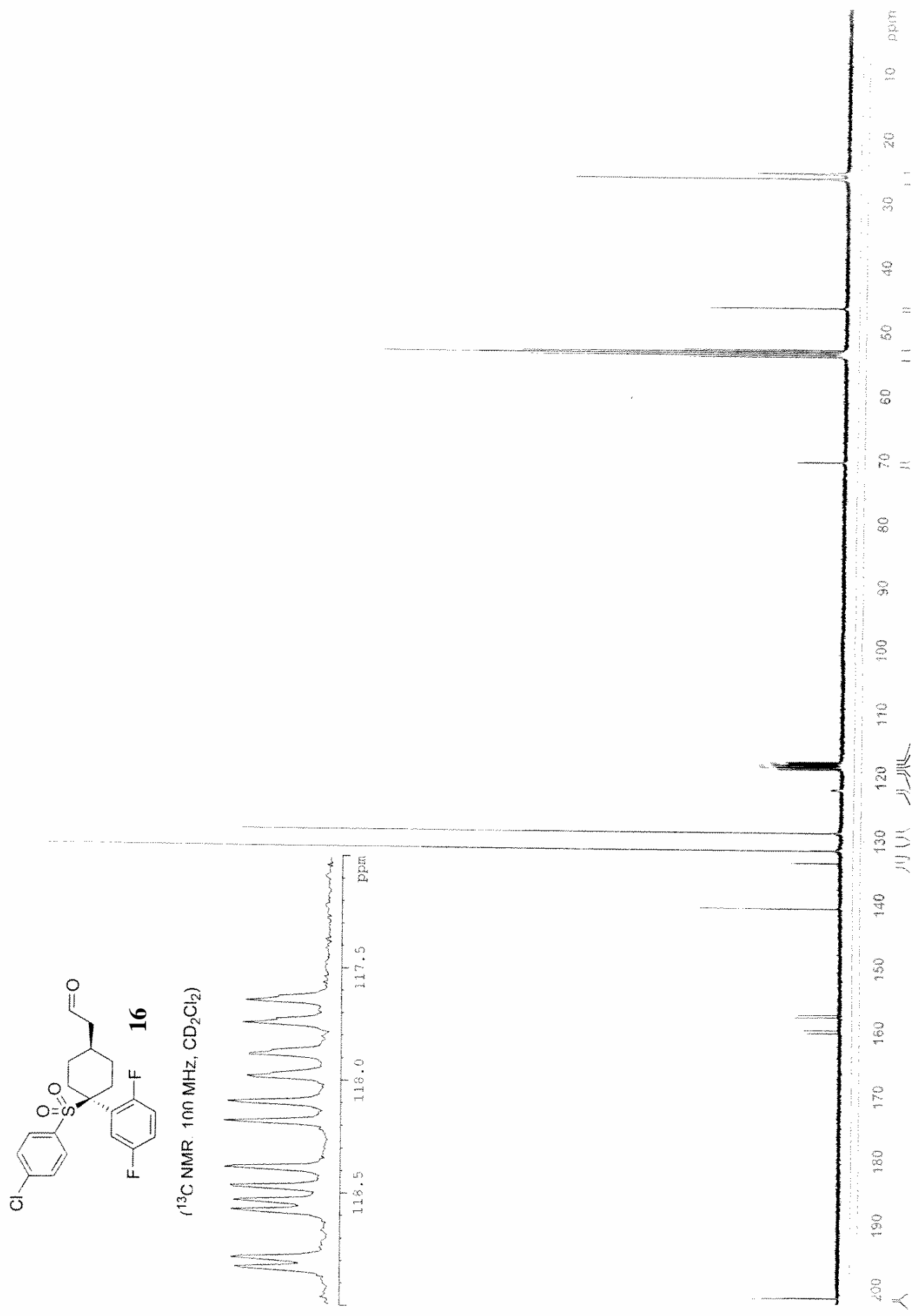




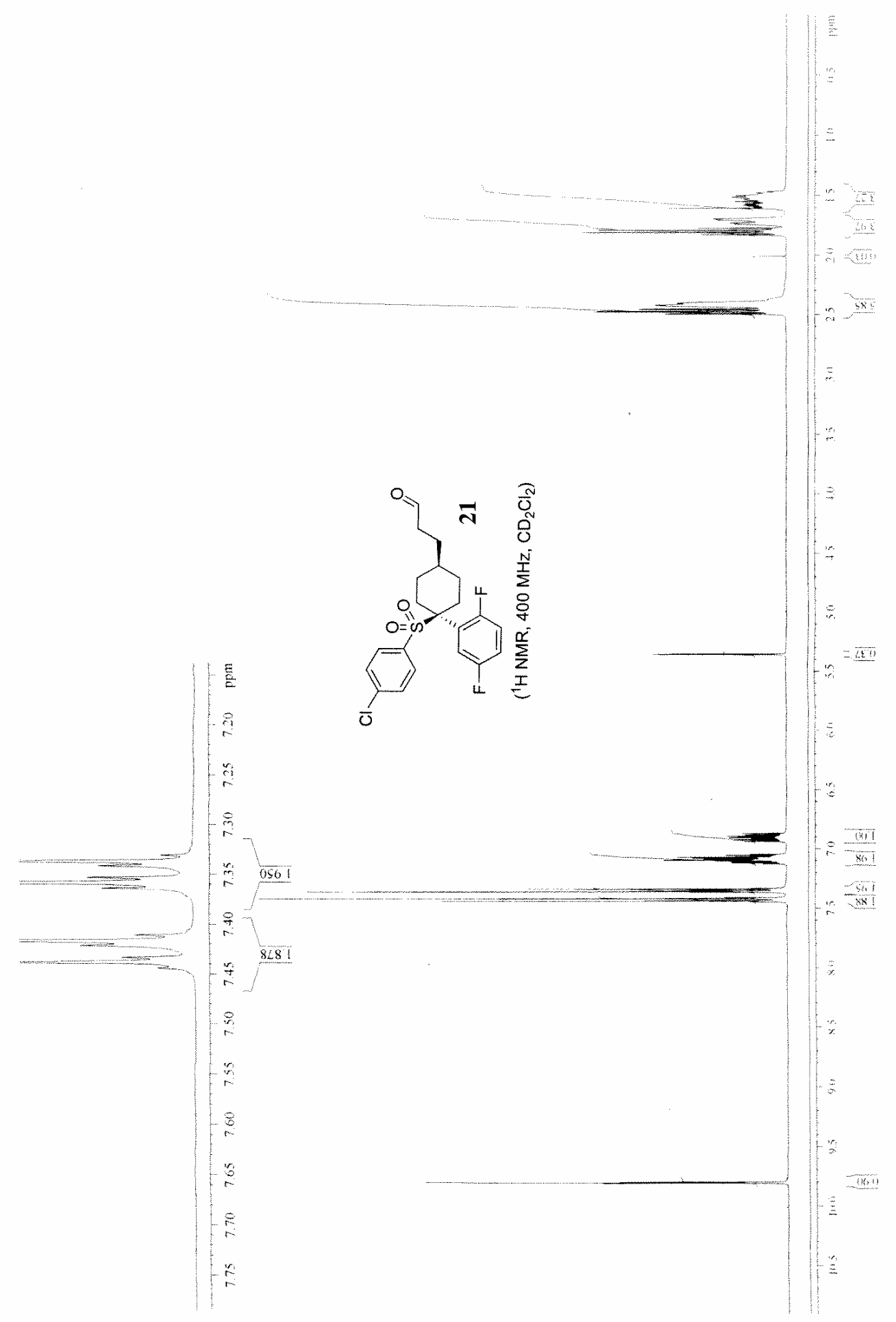




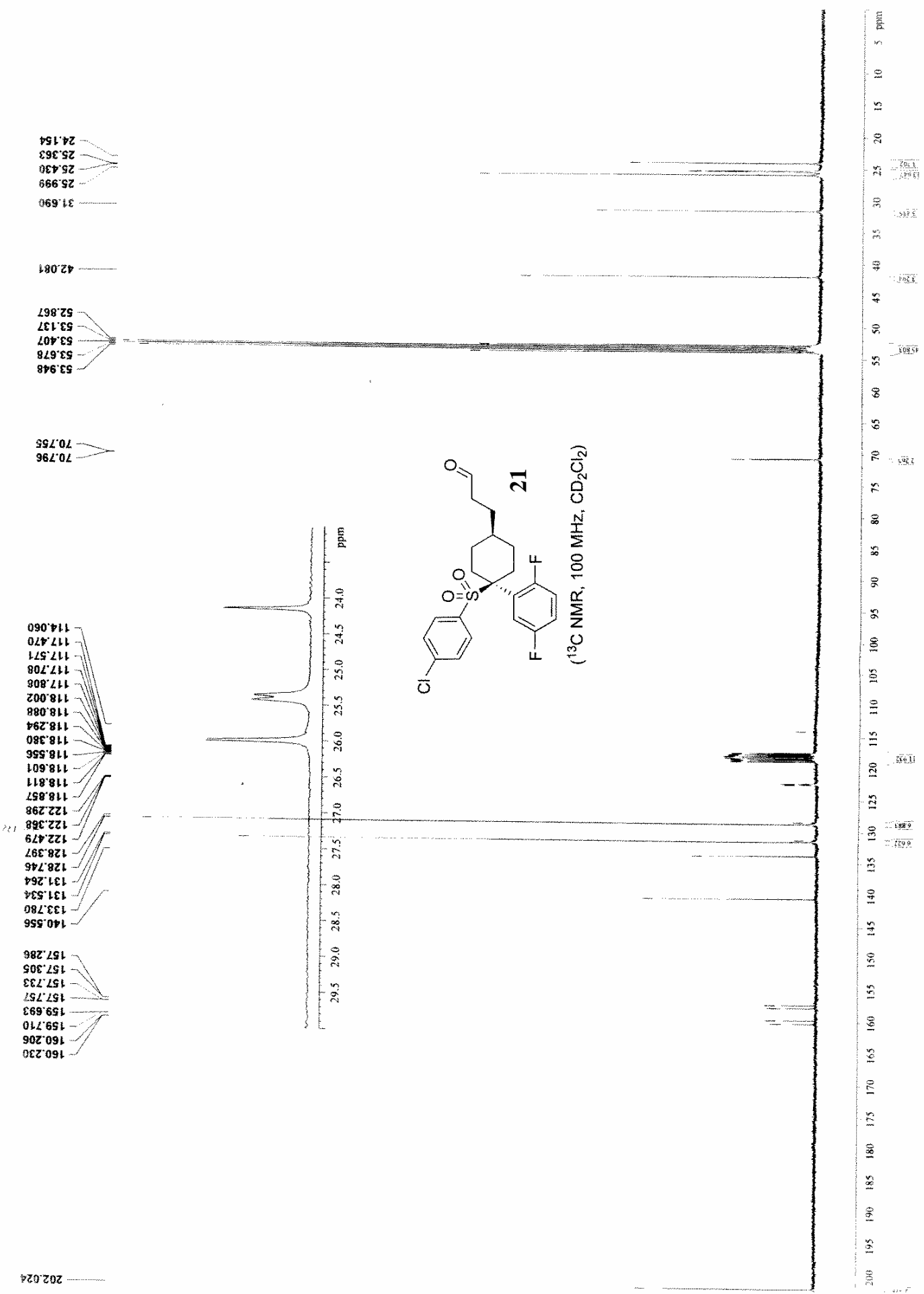




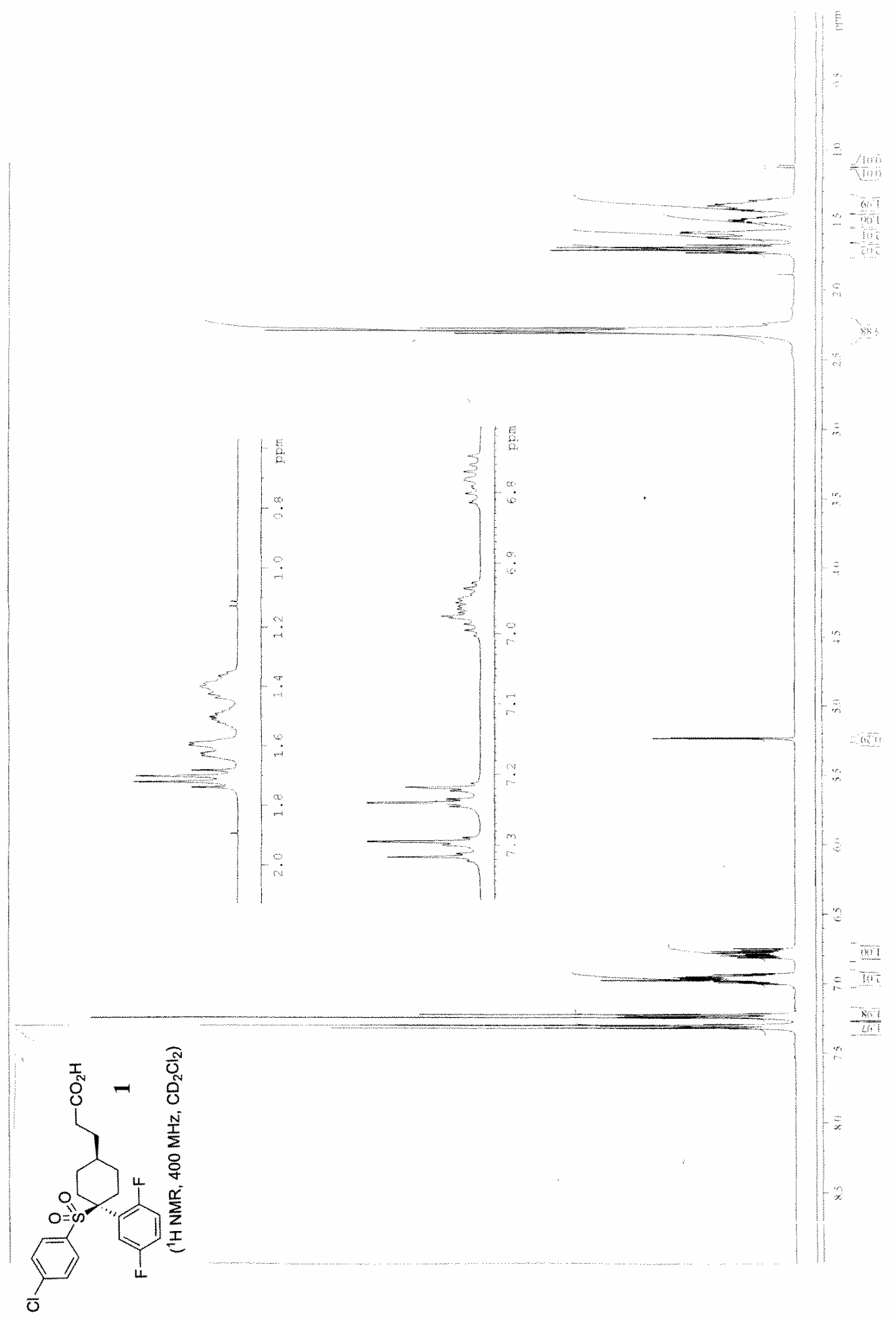




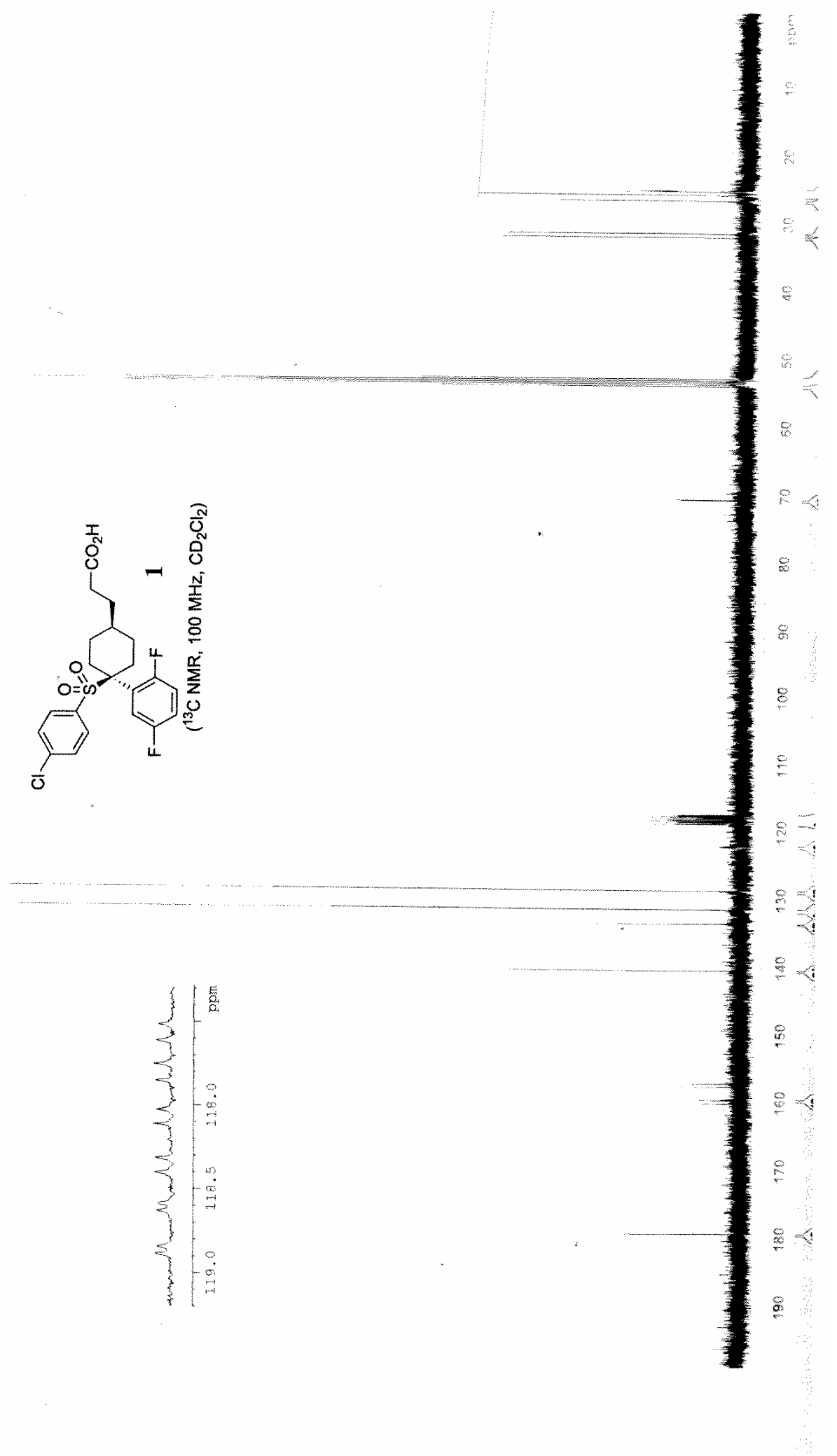



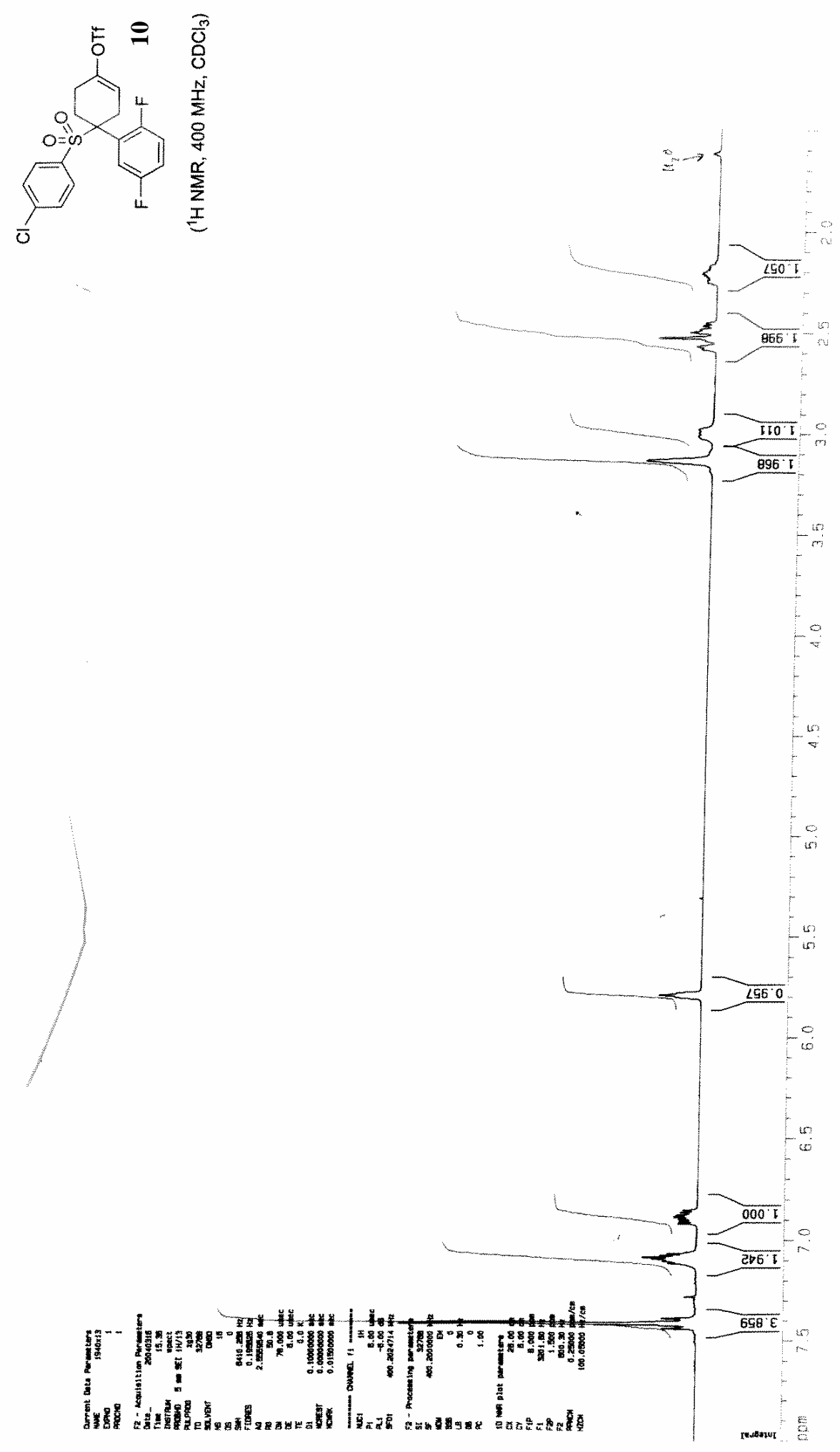

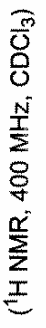




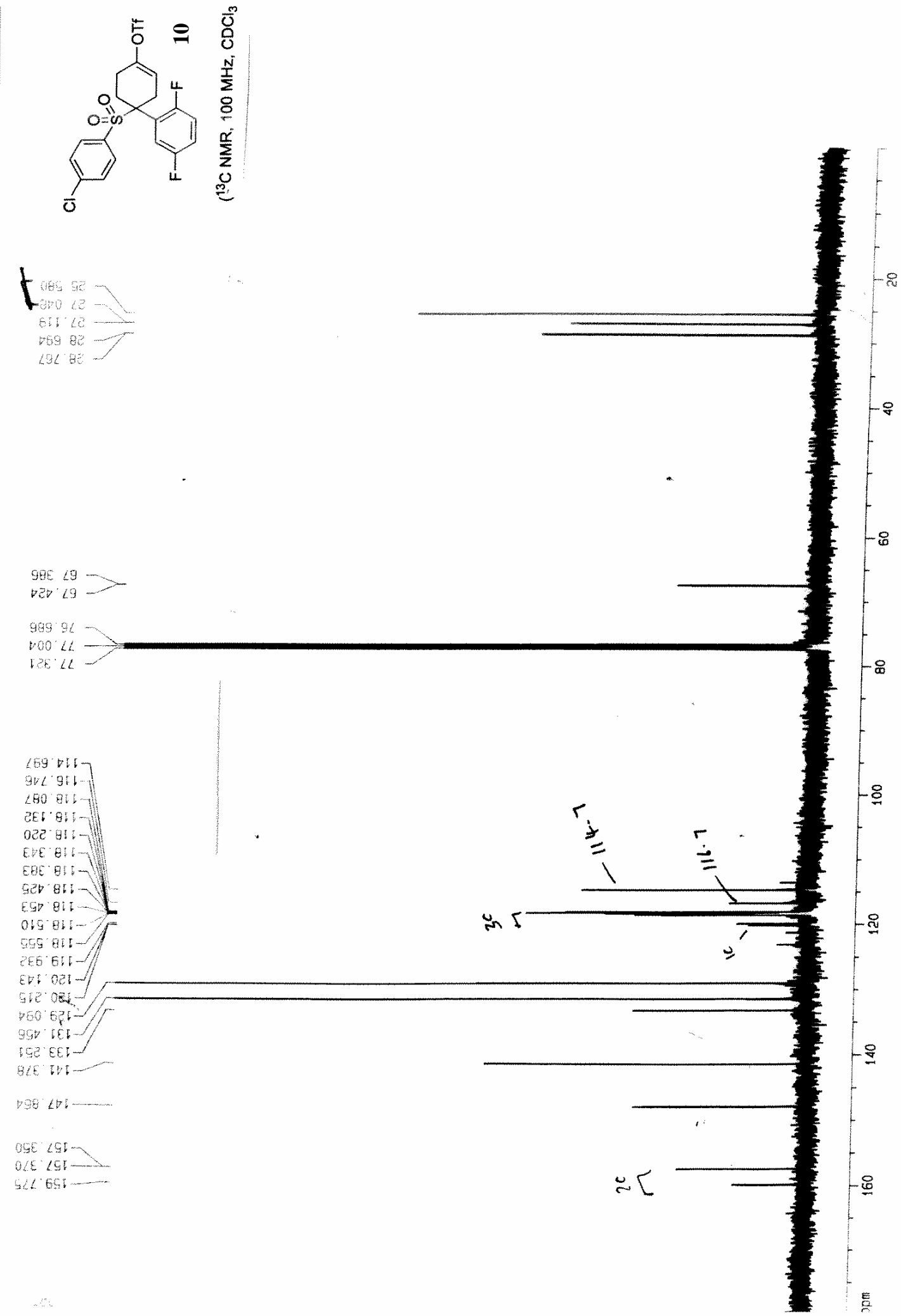




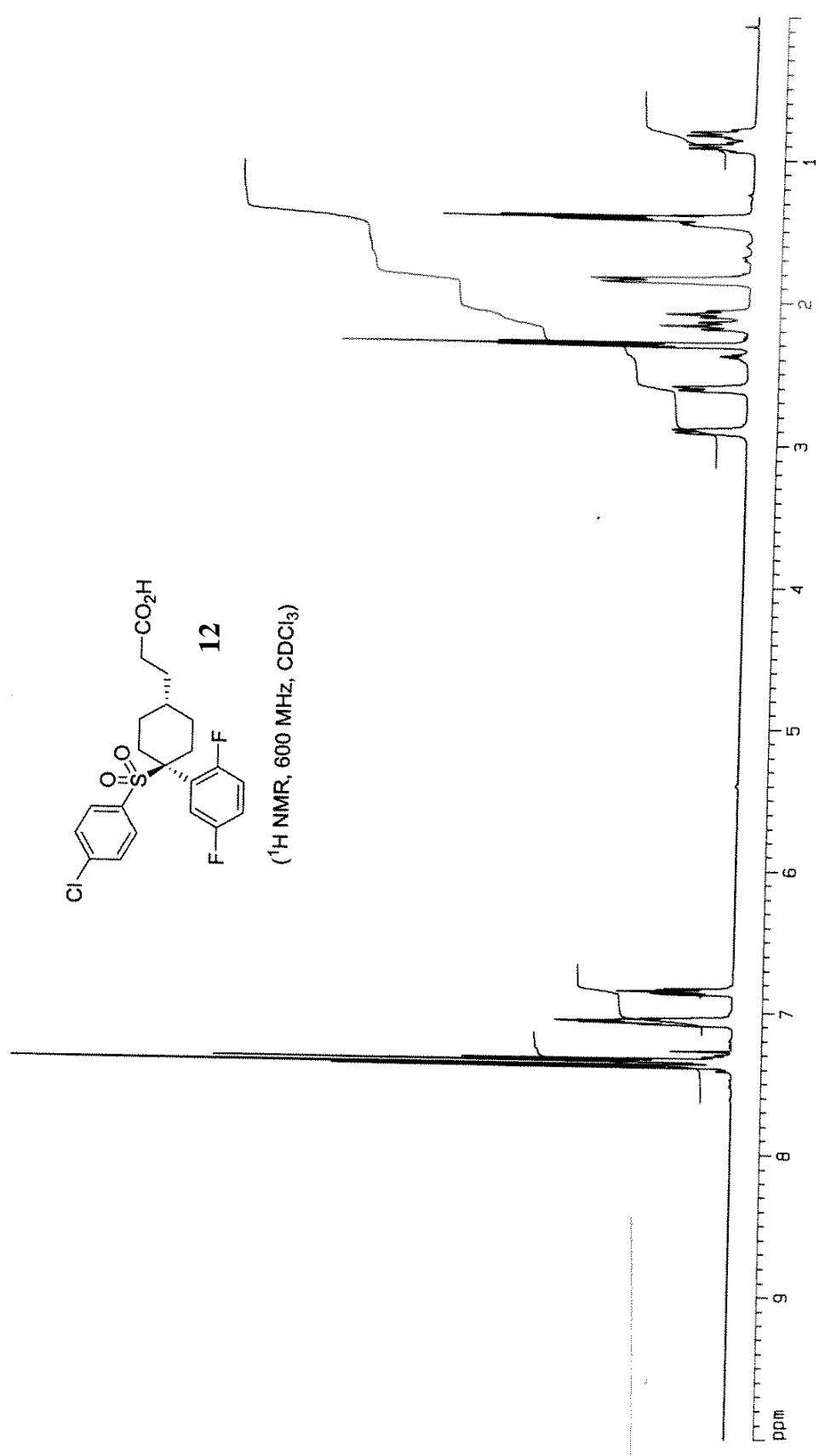




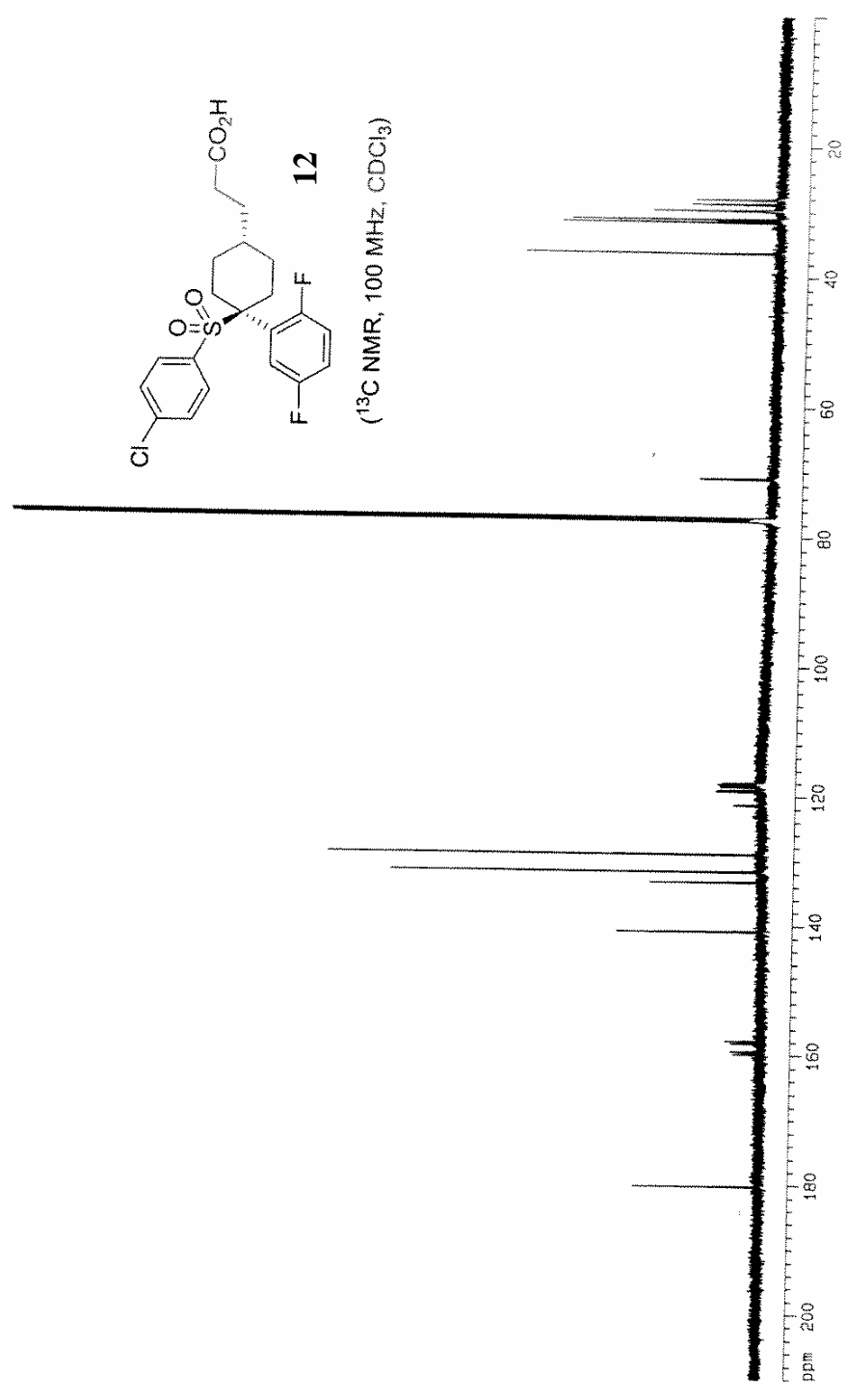

